\title{
A constructive perspective on the concept of performance according to OMPF 1802/2014
}

\author{
Doina Maria Tilea ${ }^{1}$ \\ Dragos Laurentiu Zaharia ${ }^{2}$ \\ Vasile Bleotu ${ }^{3}$ \\ ${ }^{1}$ Associate Professor, Ph.D, Faculty of International Economic Relations, Dimitrie Cantemir Christian \\ University-Bucharest, e-mail: alinat75@yahoo.com \\ ${ }^{2}$ National Research and Development Institute for Biological Sciences, e-mail: dlzaharia@yahoo.com \\ ${ }^{3}$ Associate Professor, Ph.D, Faculty of Banking Finance Accounting, Dimitrie Cantemir Christian \\ University-Bucharest, e-mail: vasilebleotu@yahoo.com
}

\begin{abstract}
From a scientific perspective, articulating the concept of performance with other notions deserves to be analyzed more rigorously. Progress in this area seems to be passed through an epistemological reflection. Constructive-inspired model proposed by Dominique Bessire associates performance with the objective dimension of reality, coherence with the rational dimension and relevance with its intentional dimension.
\end{abstract}

Key words: Performance, costs, assessment, financial, benefits

JEL Classification: M41

\section{Introduction}

The cult of performance is one of the characteristic features of contemporary Western societies. This cult for the word performance has marked several disciplinary fields. Steering performance tends to substitute the historical expression of management control, regarded as outdated as it is confessed in recently published papers or articles. The term of performance is almost invariably used in a context of assessment, in a default (steering performance, performance management) or explicit (assessment on performance) manner.

\section{The evolution of performance}

Regarding the concept of performance has remarkably evolved, so that if during the 50s all definitions and references conjured financial measures of performance, this being particularly appreciated by the couple costs / benefits, subsequently being used other measures such as the quality offered to customers (to 90s), nowadays the concept of performance has evolved to a comprehensive approach including financial aspects and also non-financial aspects, which are primarily concerned with elements of social responsibility. If on the forefront in the last century was the financial performance, economic entities nowadays have realized that this is just the result of the race, but the race itself and the determinant of success of the future race is what today, in the context of sustainable development of society, we call overall performance. Overall performance of the entity (OPE) involves the aggregation of economic, social and environmental performance. 
Performance and value are explicitly considered as a result of the action. Some authors however insist on the link between value and performance.

In most researches on performance a need to distinguish its dimensions arises. Morin, Savoie and Beaudig identify four dimensions: the social one (the value of human resources), the economic one (economic efficiency), the political one (organization's legitimacy ahead foreign groups) and the systemic one ( the sustainability of the organization).

De La Villarmois considers that these four dimensions could be reduced only to the objective (economic efficiency and sustainability) and subjective dimensions (the organization's legitimacy ahead foreign groups and the value of human resources) and states that all models proposing a representation of the concept of performance reach to the same conclusion:

- It is a concept (or a construct) difficult to assimilate because of its multiple dimensions.

Jacot and Micaelli propose the de-globalization of performance, associating to each of the four levels of decision that they retain (meta-political, strategic, tactical and operational) four levels of performance (societal, financial, commercial and physical). There is being raised delicate issues as the purpose of the enterprise, consistency between its objectives (productive, commercial, financial, social), their relevance in relation to certain purposes.

Jacot and Micaelli formulate the postulate of a link between performance, consistency and relevance.

The word consistency seems not to raise particular difficulties of definition. By coherence is meant that decisions are logical to each other (internal consistency) and in relation to a scale of preferences (external coherence). The word relevance seems to dedicate its recent success to the challenging title of the paper written by Johnson and Kaplan (Relevance Lost, 1997). Typically, relevance is defined in relation to a user and to intent. And yet, in some cases, it seems that relevance is confused with consistency; it can measure a certain ability to cover a departure from the norm or, in other cases, it is assimilated with precision, even accuracy.

These differences in interpretation have concrete consequences, as shown by the debate over accounting normalization. Colasse highlights in order to severely criticize it, the objectivist concept of relevance: it is about searching for relevance in relation with an observed object that is unique (the enterprise), as a scientific measuring device measures a size without considering many possible uses.

Performance appears either as a summation of relevance and coherence, either as a product of an iterative loop between the two terms (concept associated with the cybernetic model). These concepts, although seductive, have the great drawback that they disregard the strategic intelligence of the user. For him, coherence, relevance, and performance do not make sense and are a subject of interpretation only in relation to certain finality.

For Bourguignon, ,performance is subjective because it is the product of the operation, by its subjective nature, which consists in bringing a reality closer to a desire, ascertains the degree of success of an intention". For Lebas, ,performance is not a concept that is defined by an absolute manner".

Referring to subjectivity, Bescos draws a distinction between measuring performance and measuring results. The first is based on the relatively objective nature of the information, while the other, more subjective, would invite to an interpretation in terms of culture and value judgment. 


\section{Factors that influence the performance of the entity}

Jean-Claude Scheid recalls that until the first half of the twentieth century, accounting rather serves to establish, with caution, a situation often called "inventory" instead of "balance", than to calculate the result. The investor is looking for financial security, and the balance will come to preference in to the detriment of the analysis of profitability, and also of the economic analysis in terms of flow. The French conception of the result is consistent with the recognized priority of balance.

B. Colasse highlights that "taking into account the regulated and normalized definitions of terms income and expenses, the result is purely patrimonial and corresponds to revenues that the company procures for its owners."

Given the strength of the relations between accounting and taxation, it is not surprising at all to find that balance sheet approach on the definition that the French General Tax Code gives to the net result ,represented by the difference between the net asset value at closing and the one corresponding to the opening of the year".

In such a conception, the results account becomes, to some extent, an annex to the balance sheet that explains the change in equity, exclusively new contributions and distributions. Not to be neglected the concept of subjectivity that accompanies the concept of result and that finds its causes in the perspective of the outcome that different categories of users have, and in accounting policies and options.

If we judge the outcome from the perspective of the owners of the enterprise, it will be the difference between revenue and expenditure, including financial and personal ones. In view of the capital-bringers (either owners or banking creditors), the result is the difference between revenue and expenditure, exclusively the interest paid to creditors. J.Richard refers to this result, when he talks about the economic result.

If we widen the area and if we refer to both interests of the employees and the ones of the capitalbringers, the result will be best defined by the added value.

Within the frame of reference of French accounting, the border between expense and profit is far from being clear. It is known that among some managers of enterprises, there is a tendency to take on the salary items that would otherwise be taken on the distribution of benefits. The fact that this is a reality, and not just a French one, it is also attested by the opinions of two American economists, Cyert and March are asking themselves, "... why do we consider salaries as expense and dividends as profits ... and not vice versa? Which is in fact the role of the company, to maximize the profit or wages?"

Since the value of an enterprise or rather of its shares is no longer calculated as sum of the values of assets, but determined by its ability to generate economic benefits, the balance loses interest before the account of profit or loss, which better translates this skill. In such an approach, the result is not expressing a change in property anymore (enrichment or depletion), but it becomes an indicator of performance.

About what performance it is all about? ... But what is performance? Without giving an exhaustive and universal definition of performance, here are some meanings to which the specialized literature makes frequent reference:

- Performance equals success. Performance does not exist by itself; it is dependent on the representation of success made by the different categories of users of accounting information. 
- Performance is the result of the action. The opposite of the previous one, this understanding does not retain the value judgment of external users. Measuring performance is understood as "ex post evaluation of the results achieved."

- Performance is action. In this respect, performance is a process, not an outcome that occurs at some point.

Relating to these understandings, we can understand that performance is defined by the users of accounting information in relation to their own objectives. Thus, a definition of the performance of an economic entity, designed in a heritage context (in terms of liquidation and partition), could not satisfy a user who is placed in a context of continuity of exploitation.

Performance is not a state but a process, its content becoming almost secondary in relation to its own dynamic. This attitude is translated into practice and by the conduct of financial analysts assessing titles by multiples of the held net profit, but also anticipated.

The emergence of the account of profit and loss as a document explaining the variation of heritage is attested in the second half of the fourth century and conditioned in a significant extent by the evolution of the balance sheet.

Since the early twentieth century (1908), Eugen Schmalenbach opposes the traditional economic vision of the balance sheet an analysis that he qualifies as dynamic and which focuses on measuring the result, considered more useful for business management.

In the U.S. during 30s, W.A. Paton and A.C. Littleton are developing a model for determining the outcome, based on ,the conventional accounting theory” (conventional accounting).

Regarding the observation field of performance, two trends are binding:

a) some defend a restrictive concept of result (current operating concept);

b) while others prefer a wider definition (all inclusive concept).

The first do not want to include the account of profit and loss than the consequences of ordinary operations, normal for the current period and to impute to stock operations which do not concern the exploitation. Items specific to exploitation are considered normal, recurrent, allowing predictions of future performance and comparisons over time and space of this performance. This theory corresponds to the priority given to the account of profit and loss.

\section{Is performance a residual value?}

We tend to believe that, on the contrary, the performance is synergy, is dynamic, which is why its shape through the income statement as synthesis of flow accounting is fundamental. But achieving an optimum in terms of measuring both financial position and performance of the enterprise, it may be possible only in the context of the restriction of capital maintenance.

Therefore, we can say that, from the international perspective, the balance sheet keeps up with the income statement.

\section{Measuring financial performance through „The account of profit and loss”. Convergence / divergence}

Achieving performance is a priority objective of any enterprise, and performance-related information is of interest to a wide range of users of financial information. Most times the performance of the enterprise is 
assessed based on income statement, "the profit being frequently used as a measure of performance or as a reference for other indicators."

The main objective of financial statements is to provide useful information to investors regarding the performance of an entity. Although the information in the financial statements relates to past performance, they are used by investors to make predictions of future performance. In the financial statements, performance is measured by net income and its components which are presented in the income statement. Income statement provides information about a certain period of time.

The main weaknesses of income statement are considered to be the nature of its regular and estimates involved (the ability or inability of the enterprise to make these estimates are reflected in the accuracy with which are performance of the year are measured). For quite a period of time, performance was measured through net earnings. In recent years, in addition, performance is shown through the economic out-turn, which includes all changes in equity occurring during the period, excluding transactions with owners.

A long time users of financial statements have been limited at consulting the account of profit and loss for information on accounting result, considered the most important indicator for measuring the performance of the economic entity. On the same path lies the economic theory, noting as main objective of economic activity, maximizing profit. But freedom of choice of accounting policies by companies that result in an increase or a decrease in earnings is a major information gap of the account of profit and loss.

The account of profit and loss is the financial statement that measures the success or the performance of the activity of an entity during a period of time.

\section{Conclusions}

We can conclude that if in a balance and patrimonial approach the result tries to measure the increase of the heritage owned by the enterprise, in an Anglo-Saxon logic (and, by extension, internationally), even when it approaches a conception of balance, "primacy of economics" (assets do not correspond to property rights, but to economic resources) lead to the construction of a result as an indicator of performance.

\section{References}

1. Bennet Martin, James Peter, 1997, Environment-Related Management Accounting : Current Practice and Future Trends", GMI, 17, Spring;

2. Oprea Călin, Călin Claudiu Florin, 2007, Contabilitate managerială, Tribuna Economică Publishing House, Bucharest;

3. Bernard Colasse, 2000, Comptabilité générale, Economica Publishing House, Paris, 2000;

4. Deegan C., 2006, Financial accounting theory, 2Edition, McGraw-Hill Australia Pty Limited, Australia;

5. Verbuncu Ion, Zalman Michael, 2005, Management şi performanţă, Universitară Publishing House, Bucharest. 